\title{
VBioindex: A Visual Tool to Estimate Biodiversity
}

\author{
Dong Su Yu*, Seung Hwa Yoo \\ Department of Ecological Assessment, National Institute of Ecology, Seocheon 33657, Korea
}

\begin{abstract}
Biological diversity, also known as biodiversity, is an important criterion for measuring the value of an ecosystem. As biodiversity is closely related to human welfare and quality of life, many efforts to restore and maintain the biodiversity of species have been made by government agencies and non-governmental organizations, thereby drawing a substantial amount of international attention. In the fields of biological research, biodiversity is widely measured using traditional statistical indices such as the Shannon-Wiener index, species richness, evenness, and relative dominance of species. However, some biologists and ecologists have difficulty using these indices because they require advanced mathematical knowledge and computational techniques. Therefore, we developed VBioindex, a user-friendly program that is capable of measuring the Shannon-Wiener index, species richness, evenness, and relative dominance. VBioindex serves as an easy to use interface and visually represents the results in the form of a simple chart and in addition, VBioindex offers functions for long-term investigations of datasets using time-series analyses.
\end{abstract}

Keywords: biodiversity, computational biology, ecology

Availability: VBioindex is available at http://sourceforge.net/projects/vbioindex/.

\section{Introduction}

The Convention on Biological Diversity (CBD) defines biodiversity as "the variety of life on Earth and the natural patterns" $[1,2]$. CBD has underlined the importance of abundant biodiversity in the sustainable use of natural resources [3]. Moreover, maintaining biological coexistence for all organisms on earth, including animals, plants, and microbes, is imperative for human welfare and quality of life [4]. Thus, many researchers use quantitative measures of biodiversity in an attempt to sustain and restore ecosystems [5].

Biodiversity is generally measured by statistical indices based on the emergence and/or existence of various organisms such as plants, animals, and microbes; these indices can provide quantitative criteria with increased confidence for biodiversity $[6,7]$. Of the statistical indices, Shannon-Wiener index [8], species richness, and evenness [9] have been widely used as the gold standards, in spite of traditional methods. The Shannon-Wiener index is based on information theory and is measured using the concept of entropy, and it is applied to estimate the degree of species diversity in a region [10]. Species richness and evenness measure the number of different species per sample and the relative abundance of the different species, respectively [11].

For measuring biodiversity, there are a few non-commercial tools, such as the Vegan package in R [12], EstimateS [13], and the web-based Shannon Entropy Calculator (http:// www.changbioscience.com/genetics/shannon.html). Although they are highly useful, some of them are difficult and complicated for biologists to use, especially some programs involving $\mathrm{R}$ package. While the web-based tools are easy to use, they are not suitable for personal and/or big data sets. Furthermore, some programs do not serve any function for long-term investigations of data sets using time-series analyses for biodiversity.

We developed the VBioindex tool to aid scientists in evaluating the Shannon-Wiener index, species richness, and evenness. Additionally, this program depicts relative dominance for each species. As VBioindex supports biodiversity analyses for a given period (e.g., for a month, quarter, or year), users can easily analyze a variety of biodiversity data while applying a time-series analysis. 


\section{VBioindex}

VBioindex supports four statistical indices - the Shannon- Wiener index, species richness, evenness, and the relative dominance of species - that are widely used as important criteria to evaluate ecosystems.

The Shannon-Wiener index $\left(H^{\prime}\right)$ was designed to predict the next letter of communication in a random set of data and to quantify entropy in terms of uncertainty or information content [10]. It has been widely applied in a variety of fields, such as biology and ecology. $H^{\prime}$ is measured using entropy with the proportion of individuals $(n)$ for total emerged species $(s)$ [10].

$$
\begin{aligned}
& p_{i}=\frac{n_{i}}{\sum_{i=1}^{s} n_{i}} \\
& H^{\prime}=-\sum_{i=1}^{s} p_{i} \log p_{i}
\end{aligned}
$$

Species richness $\left(D_{M g}\right)$, known as Margalef's richness index, is a measure of the variety of species in a given area or sample [10], which is calculated based on emerged species $(s)$, and the individuals $(n)$ of total emerged species [14].

$$
D_{M g}=\frac{s-1}{\log \Sigma_{i=1}^{s} n_{i}}
$$

Species evenness $(E)$ is the degree of the distribution of individual organisms among species [15], which is measured using $H^{\prime}$ and the $\log$ of emerged species (s) [16].

$$
E=\frac{H^{\prime}}{\log s}
$$

Relative dominance $(R D)$ is the frequency of individuals of a species, which generally presents the degree of dominance for a species as a percentage [17].

$$
R D_{i}=\frac{n_{i}}{\sum_{i=1}^{s} n_{i}} \times 100
$$

VBioindex is implemented by clicking a few buttons, such as Open, Save, and some selectable radio buttons (Fig. 1A). An input data file is accepted as a tab-delimited file, labeled with the date, species name, and number of individuals (Fig. 1B). The results of the four methods are graphically represented charts with a tab-delimited text output file (Fig. 1C). Along with presenting these biodiversity indices,

VBioindex allows time-series analyses at a monthly, quarterly, and yearly basis for all statistical methods, the functions of which are useful in analyzing long-term species diversity. VBioindex is programmed in Java language (higher than version 1.7), and it can be used in all operating systems in which a Java Virtual Machine has been installed.

\section{Conclusion}

Statistical indices evaluating ecology, such as the Shannon-Wiener index, species richness, evenness, and relative dominance, are considered important criteria to sustain and restore ecosystems. Although there are a few programs for these indices, some programs are inconvenient to use and do not support various indices. We developed VBioindex, a user-friendly program that is capable of measuring the Shannon-Wiener index, species richness, evenness, and relative dominance. In addition, VBioindex offers options with which a user can analyze a variety of biodiversity data while applying a time-series analysis. VBioindex outputs a tab-delimited text file with visual charts and users can use the output text file with links to other statistical programs for a variety of ecological studies such as

(A)

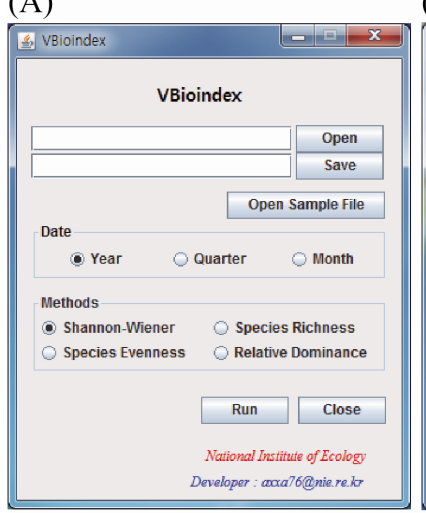

(C)
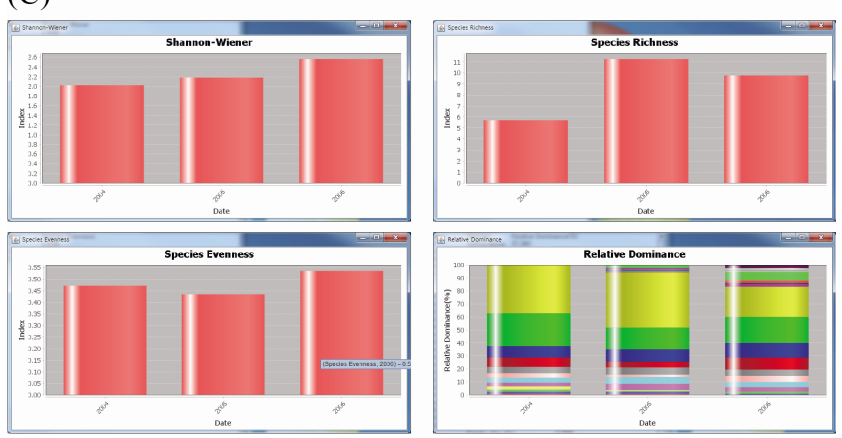

Fig. 1. Implemented VBioindex Frames: Mainframe (A) of VBioindex, input sample data form (B), and visual output charts (C) for four indices. Users can see the information such as contents and values, by waving the cursor over one of the randomly colored bars. 
comparative analyses between many datasets. VBioindex is publically accessible at http://sourceforge.net/projects/ vbioindex/.

\section{Acknowledgments}

We thank for all members of the Department of Ecological Assessment, National Institute of Ecology. This research was supported by Ecosystem Assessments in Korean Peninsula Using Integrated Ecological Data (II), funded by the National Institute of Ecology.

\section{References}

1. Puppim de Oliveira JA, Balaban O, Doll CN, MorenoPeñaranda R, Gasparatos A, Iossifova D, et al. Cities and biodiversity: perspectives and governance challenges for implementing the convention on biological diversity (CBD) at the city level. Biol Conserv 2011;144:1302-1313.

2. Rantala S, Kitalyi A, Lyimo E, Swallow B, Doggart N. Integrating livelihoods and multiple biodiversity values in landscape mosaics: from knowledge to action. In: The 3rd Tanzania Science, Technologies and Innovations Conference, 2008 Nov 5-7, Arusha, Tanzania.

3. Karasov C. Focus: who reaps the benefits of biodiversity? Environ Health Perspect 2001;109:A582-A587.

4. Cardinale BJ, Duffy JE, Gonzalez A, Hooper DU, Perrings C, Venail $\mathrm{P}$, et al. Biodiversity loss and its impact on humanity. Nature 2012;486:59-67.

5. Fjeldsaå J, Lovett JC. Biodiversity and environmental stability. Biodivers Conserv 1997;6:315-323.
6. Begossi A. Use of ecological methods in ethnobotany: diversity indices. Econ Bot 1996;50:280-289.

7. Parnell JJ, Crowl TA, Weimer BC, Pfrender ME. Biodiversity in microbial communities: system scale patterns and mechanisms. Mol Ecol 2009;18:1455-1462.

8. Jost L. Entropy and diversity. Oikos 2006;113:363-375.

9. Soininen J, Passy S, Hillebrand H. The relationship between species richness and evenness: a meta-analysis of studies across aquatic ecosystems. Oecologia 2012;169:803-809.

10. Spellerberg IF, Fedor PJ. A tribute to Claude Shannon (19162001) and a plea for more rigorous use of species richness, species diversity and the 'Shannon-Wiener' Index. Glob Ecol Biogeogr 2003;12:177-179.

11. Heip CH, Herman PM, Soetaert K. Indices of diversity and evenness. Oceanis 1998;24:61-87.

12. Dixon P. VEGAN, a package of $\mathrm{R}$ functions for community ecology. J Veg Sci 2003;14:927-930.

13. Colwell RK. EstimateS: statistical estimation of species richness and shared species from samples. Robert K. Colwell, 2005.

14. Margalef R. Temporal succession and spatial heterogeneity in phytoplankton. In: Perspectives in Marine Biology (BuzzatiTraverso AA, ed.). Berkeley: University of California Press, 1958. pp. 323-350.

15. Borneman J, Skroch PW, O'Sullivan KM, Palus JA, Rumjanek NG, Jansen JL, et al. Molecular microbial diversity of an agricultural soil in Wisconsin. Appl Environ Microbiol 1996;62: 1935-1943.

16. Pielou EC. Ecological Diversity. New York: John Wiley \& Sons, 1975.

17. MacArthur RH, MacArthur JW. On bird species diversity. Ecology 1961;42:594-598. 